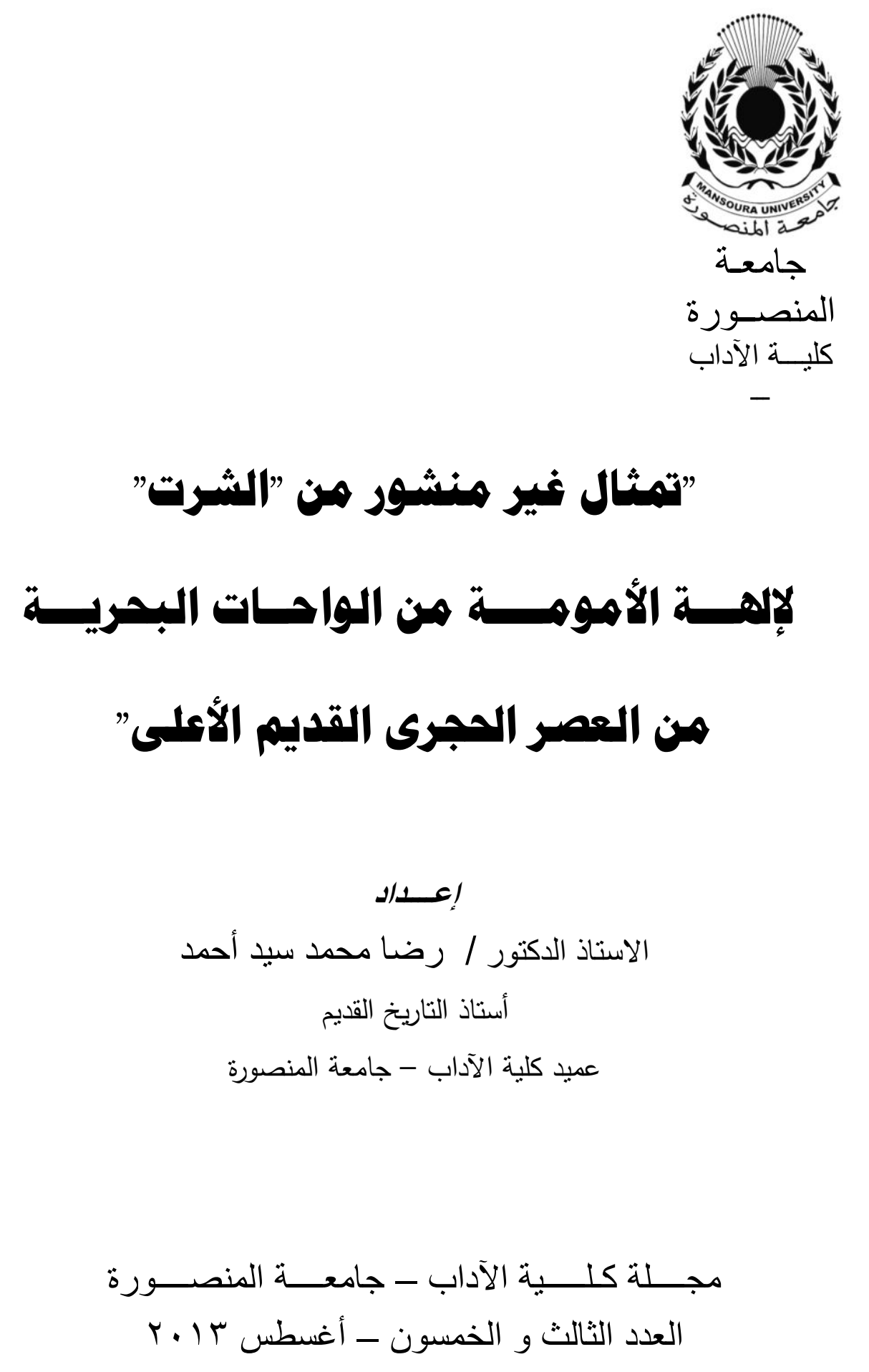




\section{"تمثال غير منشور من "الشرت" لإلهة الأمومة من \\ الواحات البحرية من العصر العجرى القديم الأعلى"}

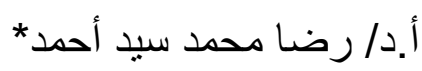

خلال الرحلة العلمية لقسم الجغرافيا لكلية الآداب - جامعة المنصورة فى مارس عام

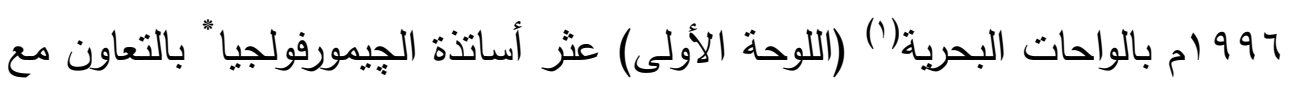

• هذا البحث نشر باللغة الانجليزية بعنوان : "Upper Paleolithic chert statue of the Mother Goddess From Baharia Oasis " in : Journal of The Faculty of Arts, Mansoura University, Supplement No. $39^{\text {th }}$ Issue. Aug-2006.

$$
\text { وهذه الترجمة العربية له }
$$

" أستاذ التاريخ القديم، وعميد كلية الآداب - جامعة المنصورة.

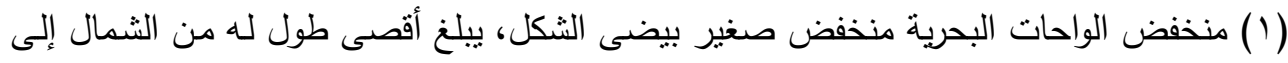

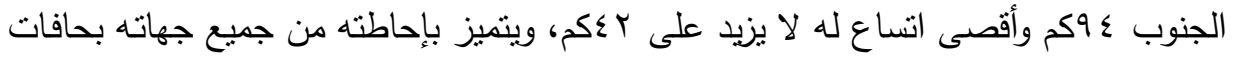

عالية شديدة الانحدار نحو قاعة، ويتميز كذلك بكثرة التلال الصغيرة، وبشكل عام يبلغ متوسط

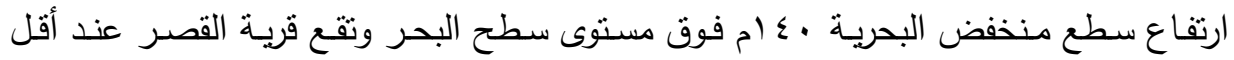

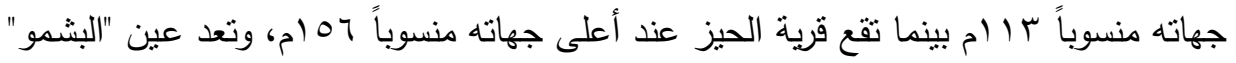

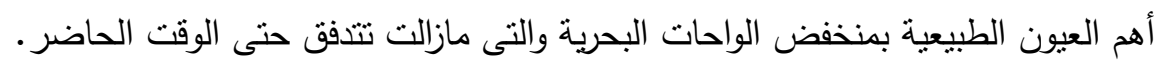

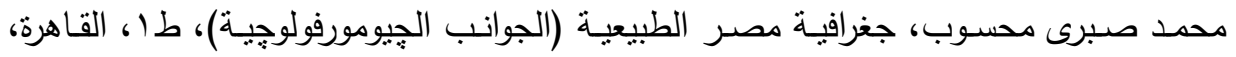

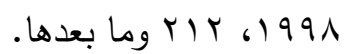

ولمزيد من التفاصيل عن هذا المنخفض جغرافياً وطبوغرافياً وجيولوجياً:

See, J. Ball and H. J. L. Beadnell, Baharia Oasis, Its Topography and Geology, Cairo, 1904 ؛

محمد صـبرى محسـوب، منذفض الواحـات البحريـة (دراسـة فـى الجغرافيـا الإقليميـة)، رسـالة

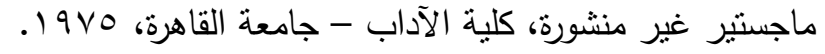

$\Lambda \cdot 1$ 
بعض أساتذة الجيولوجيا من كلية العلوم - جامعة المنصورة المرافقين للرحلة العلمية، على مجموعة من الأعمال المصنوعة من الظران والثرت(')، فى مأوى صخرى بجبل

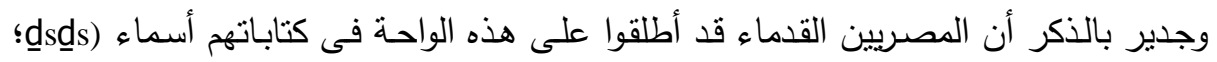
W3ḥ̣t mḥtt ؛dsds

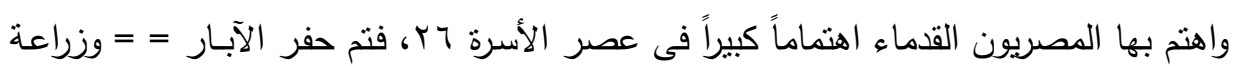
الأراضى وإنشاء الحاميات العسكرية وعثر على أربع مقابر ترجع لهذا العصر كان أصناء أصحابها من الذين يشغلون مكانة عليا بالواحة.

A. Fakhry, "Bahriija Oase" in: LÄ I, 1975, 601ff ؛

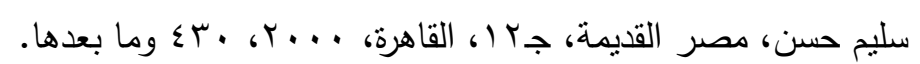

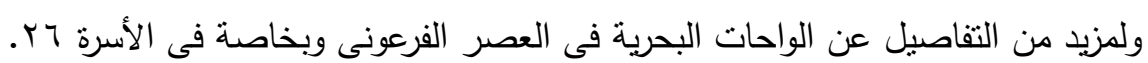
See, A. Fakhry, Bahria Oasis, 2 Vols, Cairo, 1942, 1950.

$$
\text { * الجيمورفولجيا: علم تاريخ التضاريس وأصل النشأة. }
$$

(r) الظران يكثر وجوده فى بعض المناطق بمصر فى صور عقيدات وطبقات في صخور الحجر الجيرى، ظاهره فاتح وباطنه قاتم وهو حجر صلب دقيق الحبيبات ويسهل نتكيله على الرغم من صلابته، ويتصف بسهولة شطف حوافه شطفاً حاداً قاطعاً، وسهولة فصل شظايا سليمة

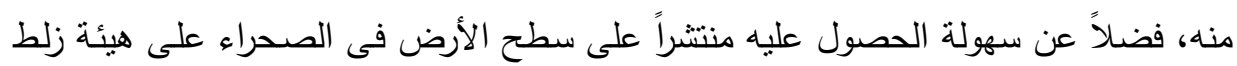

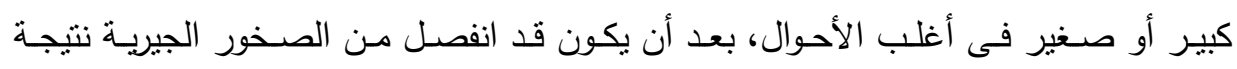

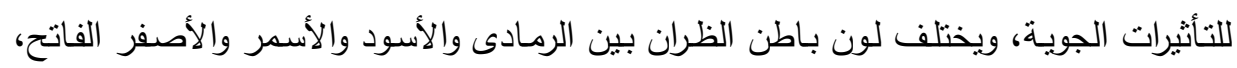

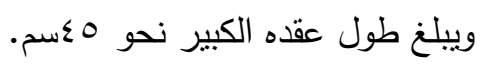

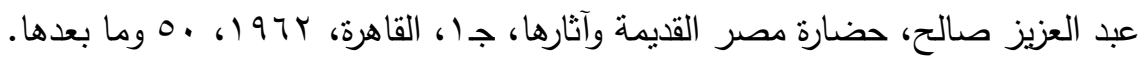

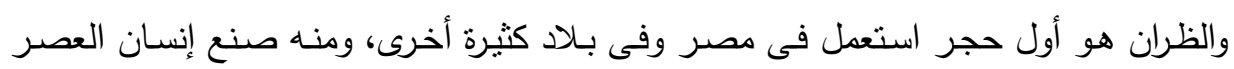
الحجرى أسلحته وأدواته وقل استخدامه بعد معرفة النحاس ولكن لم يبطل استعماله تماماً وظل مستخدماً لفترة طويلة فى أغراض معينة كان بعضها طقسياً محضاً.

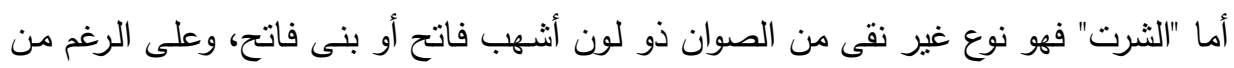

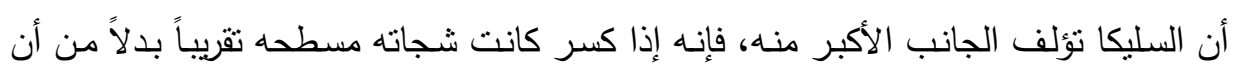
تكون صدفية الثكل كما فى الصوان، ويوجد الثرت - كالصوان - فى الحجر الجيرى وكان 
الكريستال بالصحراء البيضاء أقصى جنوب الواحات البحرية بالقرب من الطريق المؤدى إلى واحة الفرافرة (اللوحة الثانية)، وضحت آثار الصناعة المقصودة فى هذه الأعمال(') والتى تتضمن: ( () أربعة أقراص بحواف سميكة بارزة والوجه والظهر محدب يلتق حوله حز غائر ، ربما استخدمها أصحابها كمراحى لجرش الحبوب البرية بعد أن فطنوا إلى قيمتها الغذائية وعرفوا طريقة الاستفادة منها، أو استخدموها فى بعض عمليات الدق أيضا، (Y) أربعة نصال منها اثتين بهيئة شبه بيضاوية والثالث بهيئة شبه مخروطى والرابع بهيئة مثلثة الثكل، والنصال جميعها ذات سطحين وبحواف حادة قاطعة ومتعرجة فى ثلاث منها، وربما استخدمت فى تقطيع لحوم

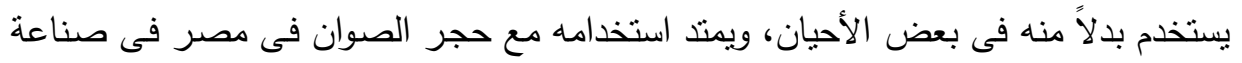

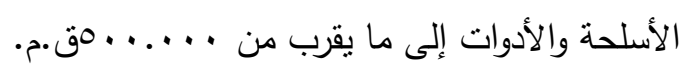

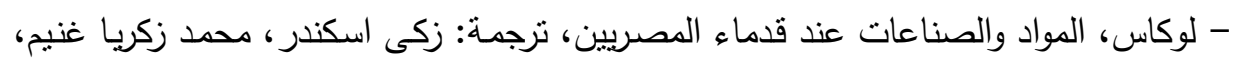

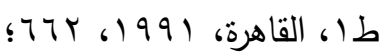

= B. G. Aston, J. A. Harrel and Ian Shaw, "Stone" in: Ancient Egyptian Materials and Technology, Ed. By. P. T. Nicholson and Ian Shaw, Cambridge, 2000, $28 \mathrm{f}$.

ولمزيد من التفاصيل عن طبيعة هذا الحجر وأيضاً استخداماته المختلفة فى عصور ما قبل

See, W. Shepherd, Flint, London, 1972, 17ff, $145 \mathrm{ff}$.

التاريخ:

(r) تعرض هذه الأعمال فى فاترينات خاصـة بالقسم كمتحف تعليمى للطلاب، إلى جانب مئات

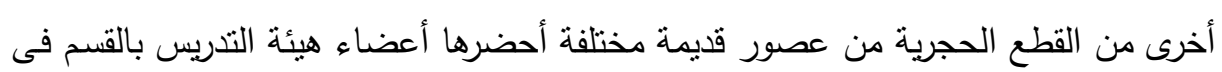

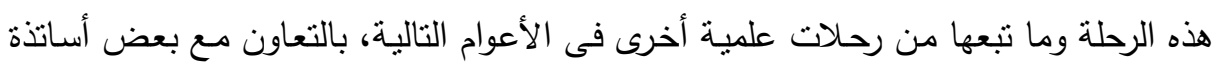

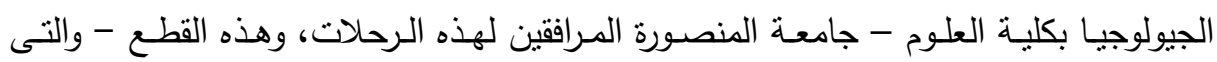
يشوب عرضها إهمال واضح وقصور شديد - كانت من أحجار متتوعة كالبازلت والديوريت

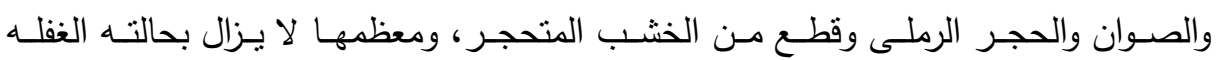

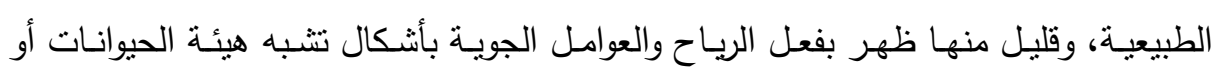
الطيور أو المراكب. 
الحيوانات وسلخ جلدها واستخراج ما يسنطيع أصحابها أكله من جذور النبات(")، (ب)

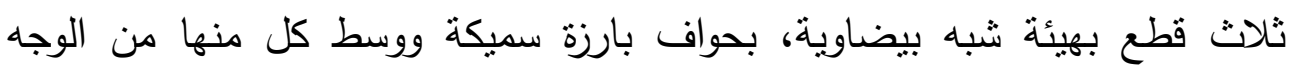

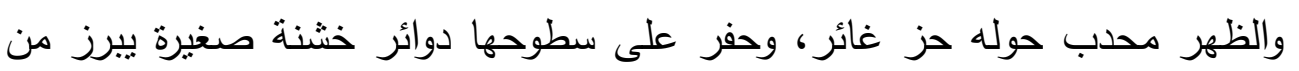
بعضها نتوء صغير فى الوسط، ووجد بها بقايا ألوان ربما كانت من بعض ولئ الأحجار

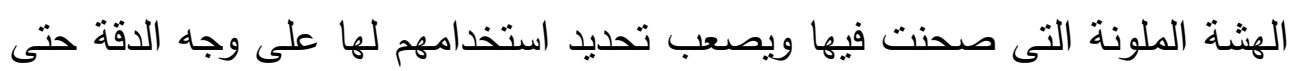

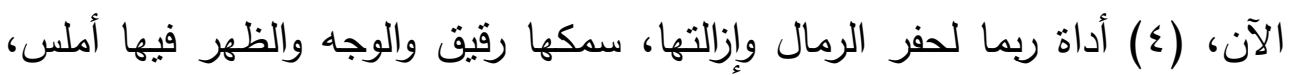

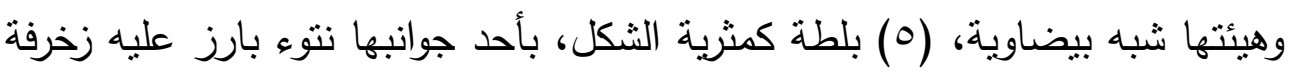

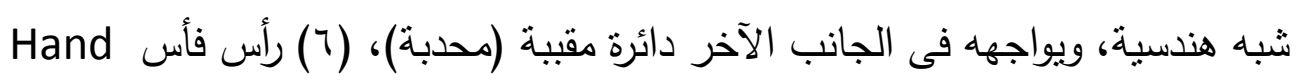
axe وجوانبها نسمح لصاحبها استخدامها فى دفاعه عن نفسه وفى مهاجمته لحيوان الصيد. (اللوحة الثالثة).

وتضمنت هذه المجموعة من الأعمال أيضاً تمثال من الثرت صناعته بدائية

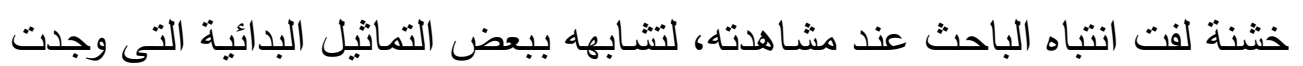

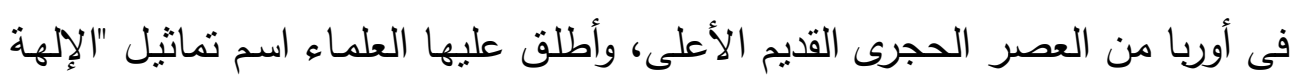

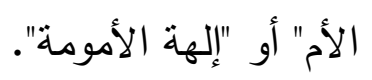

ويهذف هذا البحث إلى دراسة هذا التمثال وإلقاء مزيد من الضوء عليه كأول نشر علمى موثث له، وذلك على النحو التالى:

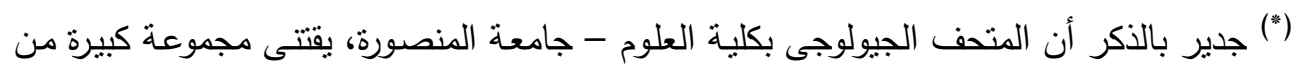

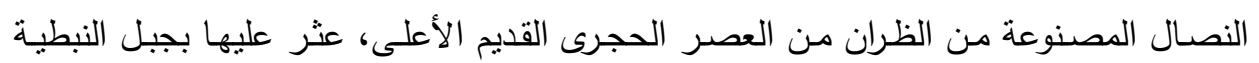
بالصحراء الثرقية، وتثبه تماماً هذه النصال. 


$$
\text { أولاً: الدر اسة الوصفية }
$$

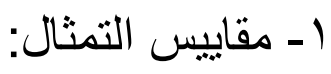

$$
\text { * الارتفاع: ع.دسم }
$$

* محيط قطر الجزء الأسفل من الجسم بالعجز : ؟ ب اسم.

* أقصى طول للجزء البيضاوى المنتفخ (الذى يمثل البطن) من جهة الجانب

$$
\text { الأيمن إلى الجانب الأيسر: هسم. }
$$

* أقصى اتساع للجزء البيضاوى المنتفخ من أسفل إلى أعلى التمنال: سام.

$$
\begin{aligned}
& \text { * ارتفاع الرقبة والرأس معاً: V.ساس. } \\
& \text { * أقصى طول للرأس: } 0 \text { ـ اسم. } \\
& \text { * أقصى عرض للرأس: ع. (سم. } \\
& \text { * محيط قطر الرقبة: ع.9سم. }
\end{aligned}
$$

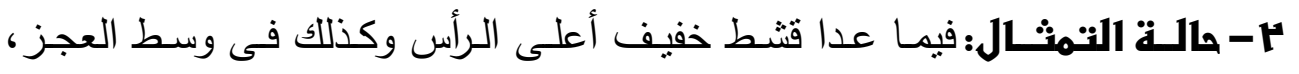
فالتمثال بحالة جيدة من الحفظ.

\section{}

يتصف هذا التمثال بالمبالغة فى إبراز مظاهر الخصوبة، وذلك بتضخيم الجزء الأسفل من الجسم والتحوير والتجريد فى الجزء الأعلى منه، فقد أبرز الفنان العجز بشكل كبير وبتضح ذلك جلياً إذا نظرنا إلى التمثال من الجانب، وأظهر أيضاً بوضوح إمتلاء البطن وإنتفاخها والتعبير عن ذللك بحفر غائر لإطار بيضاوى وسطه مقبب (محدب) قليلاً ربما تعبيراً عن الحمل. 
أما الجزء الأعلى من الجسم فقد بالغ الفنان فى تجربد عناصره وبخاصة ملامح الوجـه والرأس والتىى أظهرهـا كرأس أحد الطيور الجارحـة، وإن أبرز على إستـحياء وبطريقة خثنة ملامح العين والأنف والأذن اليسرى، وترتدى السيدة قلادة حول العنق عبر عنها الفنان بحز بارز يلتف من أمام على الصدر ، والرأس إذا نظرنا إليها من ولن ولن الجانب تميل قليلاً إلى الأمام.

وقد أهمـل الفنان تمثيـل الأطراف كالذراعين والسـاقين وكذا الثديين كما هو

الحال فى معظم التماثيل التى ظهرت فى أوربا فى العصر الحجرى القديم الأعلى ('). والتمثال يميل لونه إلى البنى الفاتح، وإن كان لا يزال على بعض أجزاءه بقايا

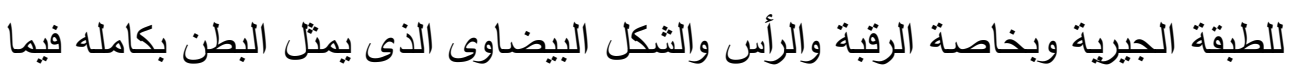
عدا الجزء المقبب (المحدب) فى وسطه وأيضاً الإطار المستدير الغائر حول العجز . والتمثال بشكل عـام صـناعته بدائية خشنة، وإن كان يحسب للفنـان فى هذه العصـور البعيدة قدرتـه على التعامـل مـع هذا الحجـر الصـلب وتشـكيله، واهتمامـــ بـالتعبير عن إبراز فكرة الأمومـة ومظـاهر الخصـوبة أكثر مـن اهتمامسه بالتفاصسيل الدقيقة كهدف اسمى صنع من أجله هذا التمثال. (اللوحة الرابعة).

ثانياً: الدر اسة التحليلية

بمثل بروز العجز أبرز مواضع الخصوبة التى تأكدت فى هذا التمثنال، شأنه

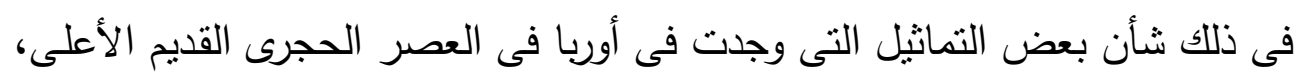

أثشرف زكريا، تماثيل ورموز الأمومة فى مصر وبلاد الثرق الأدنى القديم فى عصور ما قبل

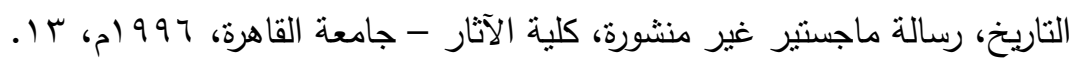


تمثال غير منشور من "الشرت" لإلهة الأمومة من الواحات ..... أ.د. رضا محمد سيد أحمد

وقد رأى العلمـاء فـى ذلك أنه ربمـا نوع من الإثارة الجنسية(')، أو أنه كدليل على الإرتباط بـالأرض والإزتباط بطقوس الخصوبة السحرية(r)، بينما يعبر إمتلاء البطن

بالتمثال عن إحتمال أن المرأة فى حالة الحمل ().

هذا ويلاحظظ أن الفنـان قـ أهدـل فـى تمثيـل ملامـح الوجـه والـرأس فـى هـذا

التمثال، مثلما هو الحال فى بعض التماثيل التى وجدت فى أوربا من العصر الحجرى القديم الأعلى أيضاً، وربما نشأ ذلك من الخوف السحرى حيث لـ يفرق الفنان بين الواقع والصـورة، ولذا ركز على مناطق الخصوبة فقط بالتمثنال(؛)، أو ربمـا أن ذلك الك يمنل إنكاراً للصفة الإنسانية لصالح القوة السحرية(*)، باعتبار أن الرأس مجرد ملحق

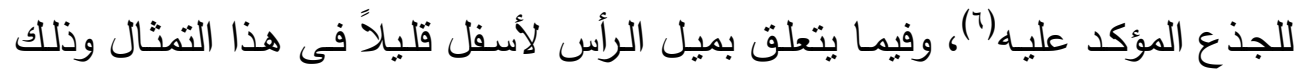

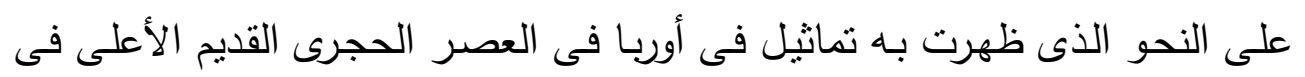

Wipf, "Phänomene Des Göttlichen in Urgeschidstlichen Zeit" in: JPR II, 1988, 35.

E. Neumann, The Great Mother, New York, 1955, $97 \mathrm{f}$.

وعن إطلاق اسم "Steatopygous" على التماثيل بارزه العجز ، وربطها بمظهر بعض الأجناس

$$
\text { الظر : أنشرف زكرية والهوتنتوب في أفريقيا. }
$$

See, N. K. Sandars, Prehistoric Art in Europe, Baltimore, 1968, 15.

G. Clark, World, Prehistory, An Outline, Cambridge, 1962, 82.

G. Levi, The Gate of Horn, New York, 1963, 58.

H. Delporte, L'Homme et Son Image, Paris, 1989, 156.

E. Neumann, Op. Cit, $96 \leq$ L. Woolly - J. Hawkes History of

Mankind, Vol I, London, 1963, 199. 
جريمالدى وكوستتكى وكيوتسا وفيلندورف، فربما يرجع سبب ذلك إلى التركيز على مركز الجسد والميل نحو الأرض(")، أو إنحناءاً على طفل غير مرئى (؟).

أمسا عن إهمال الفنان فى هذه التماثيل لتمثيل الأطراف كالذراعين والسـاقين،

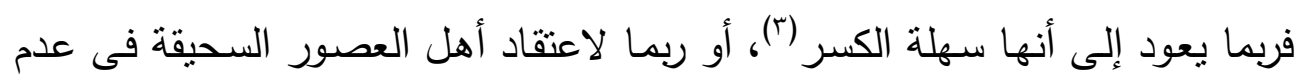
تمثثلها ما يمنع التمثنال من الهروب من خدمة صـاحبه(؛)، أو ربما فى عدم تمثنلها

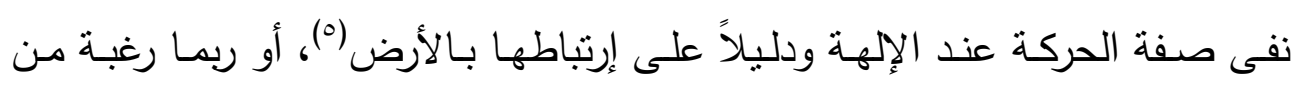
الفنان فى الإكتقاء والتلخيص والتركيز على مواضع الخصوبة ودون الإهنمام بعناصر

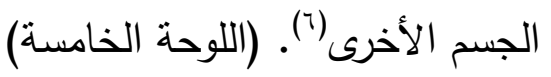

هذا وربما كان صغر حجم هذا التمثال (ارتفاعه ع.دسم)، كتماثثل الإلهة الأم التى وجدت فى أوربا من العصر الحجرى القديم الأعلى وتراوح إرتفاعها ما بين (ع -

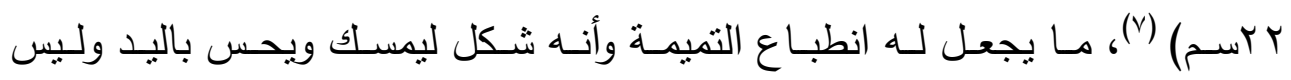
بالعين (^)، وربما تأثز سطح التمثال الخارجى وفقد بعض من لونه الأصفر فى بعض بله أجزائه لهذا السبب. ثالثاً: ت تأريخ التمثال

E. Neumann, Op. cit, 97.

G. Levi, Op. Cit, 57.

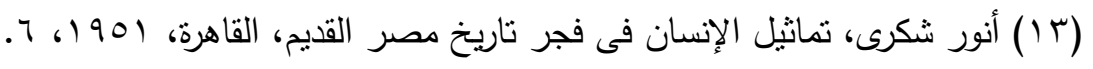

H. Kees, Totenglauben und Jenseitsvorstellungen der Alten Ägypter,

Leipzig, 1926, 43.

E. Neumann, Op. cit, 97.

$$
\text { (7 (1 ) أنشرف زكريا، المرجع السابق، } 0 \text { ؛. }
$$

J. Mariner, The Gods of Prehistoric Man, London, 1960, 109.

S. Giedion, The Eternal Present, Washington, 1957, 436. 
تمثال غير منشور من "الشرت" لإلهة الأمومة من الواحات ..... أ.د. رضا محمد سيد أحمد

يرجح الباحث تأربخ هذا التمثال بالعصر الحجرى القديم الأعلى (')، معتمداً على القرائن التالية: - ملية

1- أن أسـاتذة الجيمورفولجيـا قـد ذكـروا بـأن ملامـح هـذا المـأوى الصــرى بجبـل الكريستال بالصحراء البيضاء بجنوب الواحات البحرية، والذى وجد به هذا التمثال قد تبلورت صورته الجيمورفولجيـة خـلال العصر الحجرى القديم الأعلى، والذى شهدت مصر خلاله تغيرات مناخية إرتبطت بها عمليات التشكيل الخارجية، وقد أكد أسـاتذة الجيولوجيا بكلية العلوم - جامعة المنصورة المرافقين للرحلة العلمية

(9 (1) العصر الحجرى القديم الأعلى هو أحدث فترات العصر الحجرى القديم، وقد ظهر خلالهـ

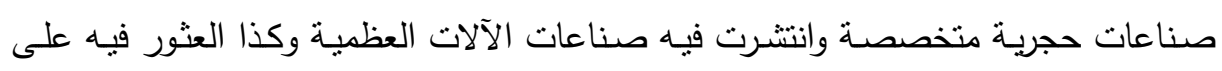

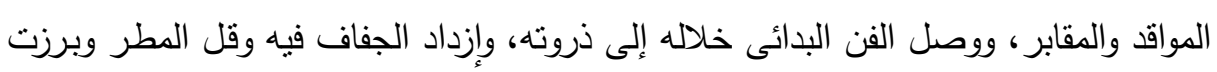
خلاله الصبغة المحلية للحضارة المصرية. مصطفى عامر، حضارات عصور ما قبل التاريخ، مقال فى: مجلد تاريخ الحضارة المصرية،

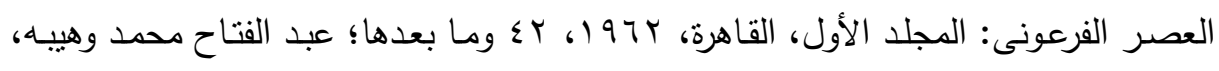

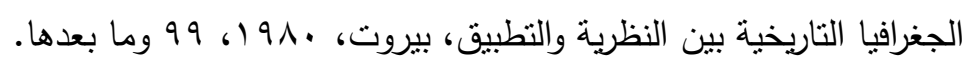

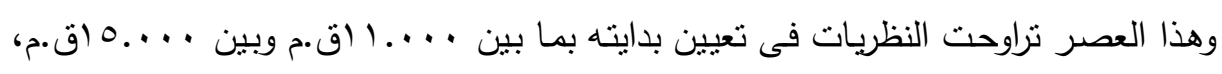

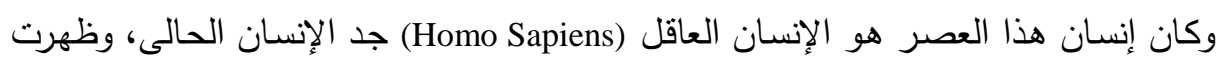

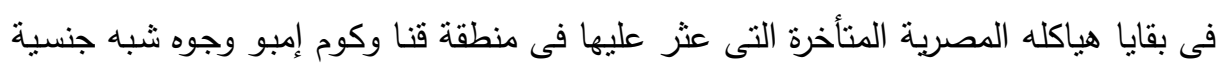
قريبة من خصائص الهياكل المصرية التى تخلفت من عصر ما ما قبل الأسرات.

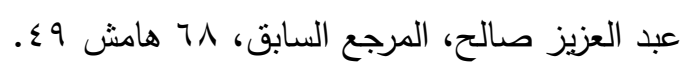

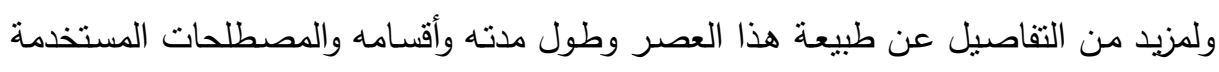

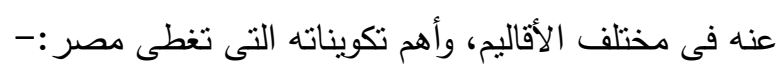

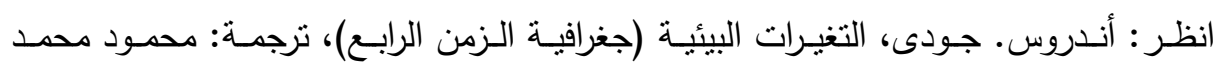

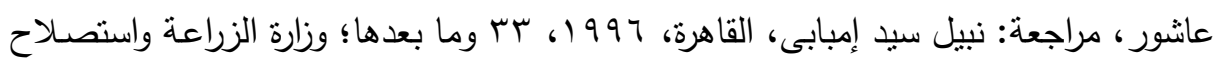

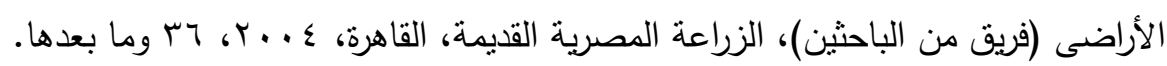


بعد تحليل عينـات من صـخور هذا المـأوى الصـخرى بمعدل أبحـاث الصـور والمعادن بالكلية على وجود حفريات بها من تلك التى تتنمى للعصر الحجرى القديم الأعلى.

r- أن الأعمال التى وجدت بالمأوى الصخرى نفسه مـع هذا التمثال ووضحت فيها آنار الصناعة المقصودة، قد ظهر لها ما يشبهـا ضمن مخلفات العصر الحجرى

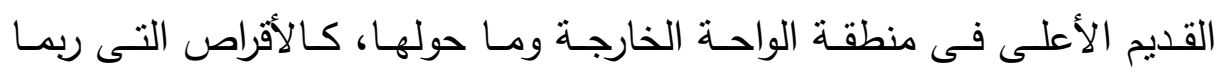
استخدمها أصحابها كمراحى لجرش الحبوب البرية آنذاك، والنصسال المخروطية أو البيضـاوية أو على شكل المنلاث، وأيضـاً Hand-axe التى كانـت بقاعدة ملساء مناسبة لقبضة البد منل Hand-axe التى وجدت بهذه الأعمال بالواحات

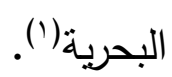

ب- أن الواحات البحربـة ومعها مناطق أخرى كثيرة بالصحراء الغربية كانت عامرة بالحياة والسكان فى هذه العصور البعيدة قبل أن تطل عليهم موجات الجفاف فى بـ بـ أواخر العصر الحجرى القديم الأعلى ويتجهوا إلى ضفاف النيل فى أوائل العصر

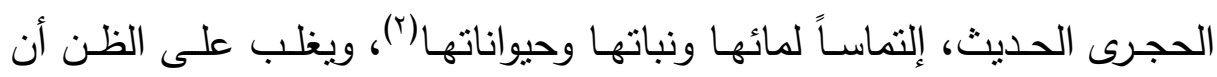

( · • ( ) عبد العزيز صالح، المرجع السابق، 79 وما بعدها؛ C. Aldred, Egypt to the end of the old kingdom, London, 1982, 15f, fig. 1.

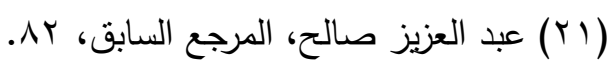

جدير بالذكر أنه عثر فى إحدى واحات الواحات البحرية وهى الحيز إلى الجنوب على مجارش

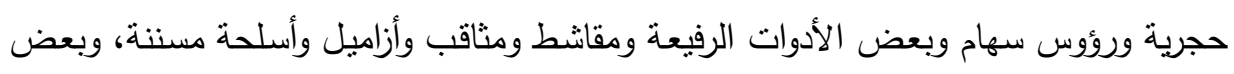

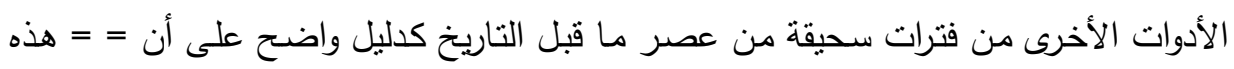

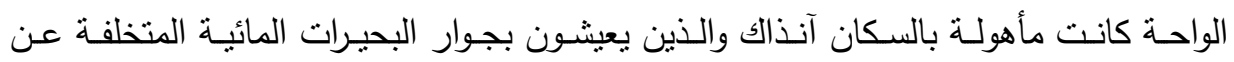

$$
\text { الأمطار - الواحة }
$$

انظر : وزارة الزراعة واستصلاح الأراضى (فريق من الباحثين)، المرجع السابق، سه؛. 
مجتمعـات هذه المناطق قد إعتمدت فى العصدر الحجرى القديم الأعلى على الترحال: الصيد والجمع مثلما هو الحال فى المجتمعات التى وجدت بها التماثيل التجريدية للإلهة الأم فى أوربا فى العصر نفسه وإرتبطت حياتها أيضاً بالترحال:

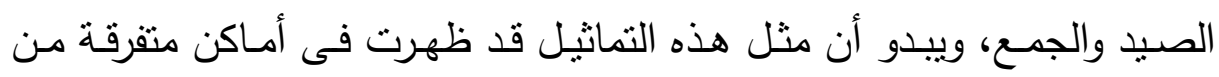
العالم القديم منذ العصر الحجرى القديم الأعلى، وإرتبطت بعبادة إلهة عالمية أطلق عليها العلماء اسم الإلهة الأم، وإنتشرت فى ربوع العالم القديم الذى لم تكن هنالك حدود أو فواصل تمنع من إنتقال عبادتها من مكان لآخر وتوظيف أهل كل مكان لها وفق ما يناسب ظروفه البيئية والمعيشية والدينية. ع - هذا التمثال يشبه مجموعة من التماثيل الحجرية التجريدية التى وجدت فى أوربا من العصر الحجرى القديم الأعلى (')، بعضها لا يمكن اعتبارها تماثيل أنثى إلا إذا نظرنا إليها من الجانب، حيث ركز الفنان على بروز العجز فقط، وقد عثر

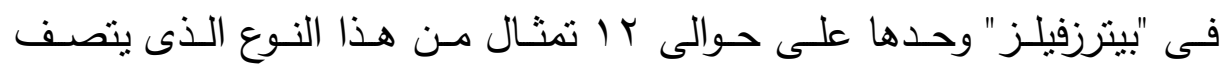
بالتحوير الثديد لجسم الأنثى (r)، والبعض الآخر يجمع بين صفة بروز العجز

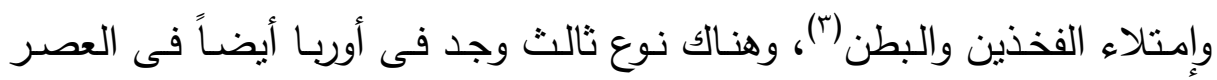
الحجرى القديم الأعلى، جمعت نماذجها بـين هيئة رقبـة ورأس الطـائر وعجز

(Yr) جدير بالذكر أن هذا النمط من التماثيل التجريدية والذى يشبه تمثال الواحات البحرية، كانت

$$
\begin{aligned}
& \text { له الغلبة في أوربا فى العصر الحجرى القديم الأعلى. }
\end{aligned}
$$

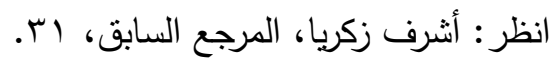

A. Marshack, The Roots of Civilization, London, 1991, 286.

S. Giedion, Op. Cit, 442.

(Y0) هذا النوع من التماثيل استمر فى شرق أوربا فى العصر الحجرى الحديث: See, M. Gimbatas, The Language of The Goddess, London, 1989, 322. 
وهذه المجموعة من التماثيل تتصف فى التأكيد على بعض مواضع الخصوبة

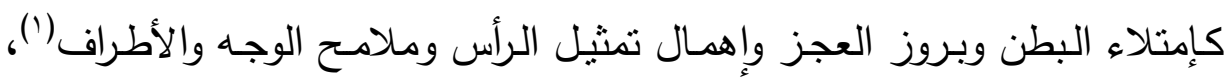

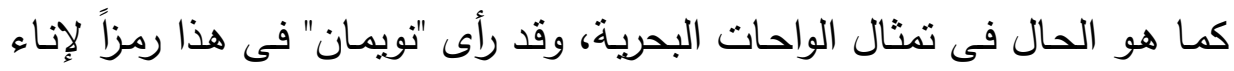
أنثوى ممتلى مستدير يمثل الطراز العتيق للأم الكبرى(؟). وتتفق هذه التماثيل التجريدية للإلهة الأم فى أوربا فى العصر الحجرى القديم

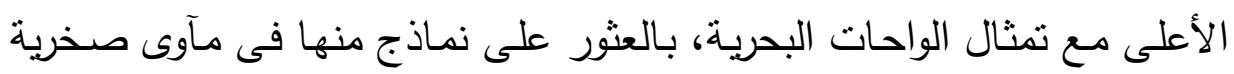

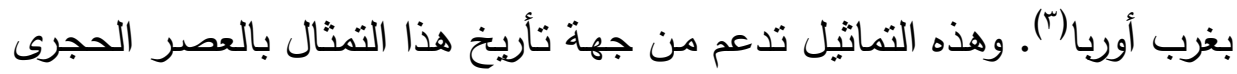

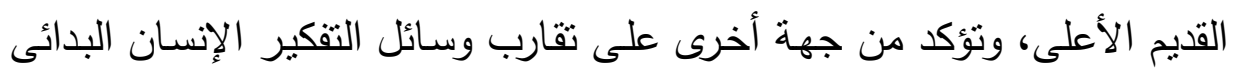
القديم وتتابه الأغراض التى يستخدم أدواته فيها ومن أجلها.

$$
\text { رابعاً: الغرض من التمثال }
$$

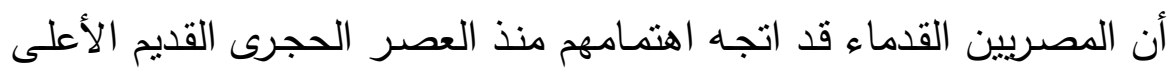
إلى الإيمان بالبعث والخلود، الذى لم تتضح فى آيات حب الخلود بمثل هذا البيان

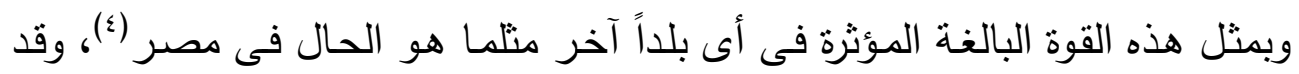

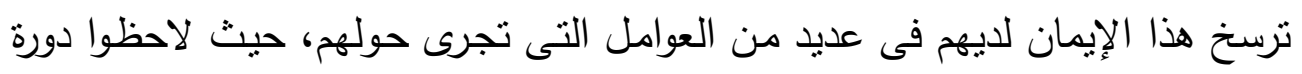

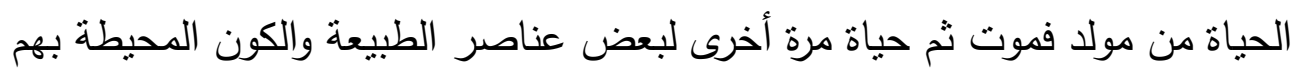

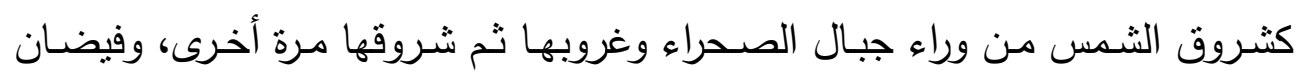

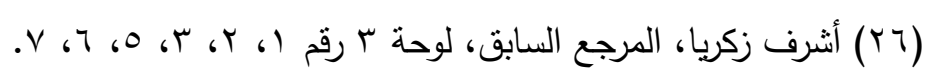

E. Neumann, Op. Cit, 96ff.

S. Giedion, Op. Cit, 453.

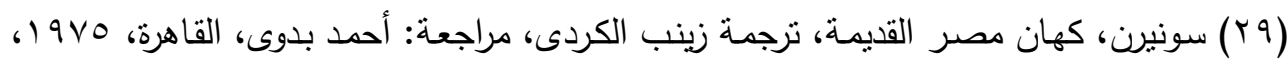


النيل الذى يغمر الأرض ثم انحساره بعد أن يترك غرينه الذى أكسب الأرض خصوبة

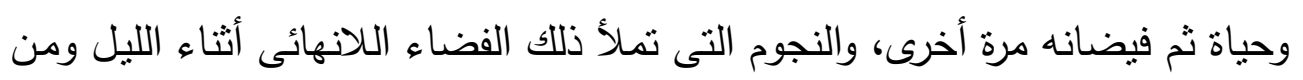

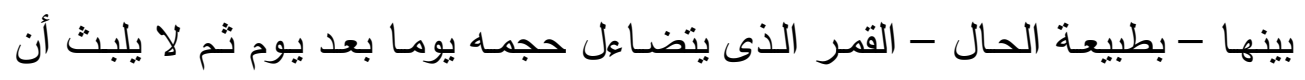
يختفى ثم يعود إلى الظهور فيزداد حجمه حتى يكتمل (').

ويعد توسيد الموتى بشكل أو بآخر فى وضـع منحنى (قرفصساء) منذ هذا

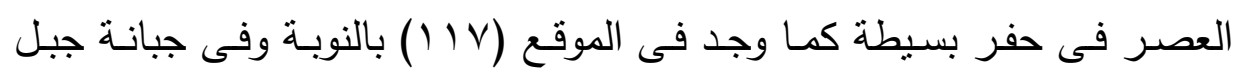
الصحابة(r) أحد أهم مظاهر إهنمام المصربين منذ هذا العصر بموتاهم والإعتقاد

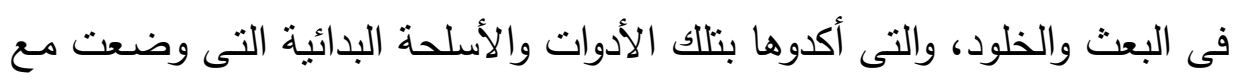
الموتى لإعتقادهم بضرورتها لهم وإستمرار الحياة بعد الموت، وتصور إنسان هذه الفترة أن له حياة بعد الموت منل حياته الأولى على الأرض (ז)، ويغلب على الظن

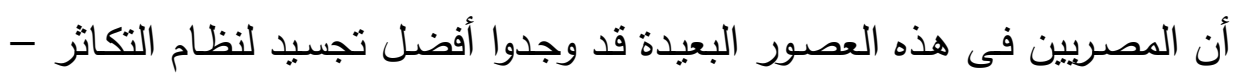
الخصوبة والبعث والتوالد والخلقه - فى تماثيل للإلهة الأم، وهو ما يتفق أغلب

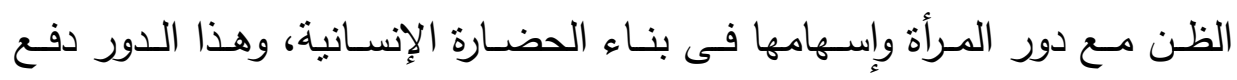
البعض إلى الاعتقاد بوجود عصدر أمومى حكته وإمتلكتهـ المرأة واقعاً وفكراً

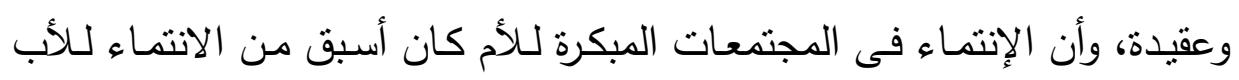

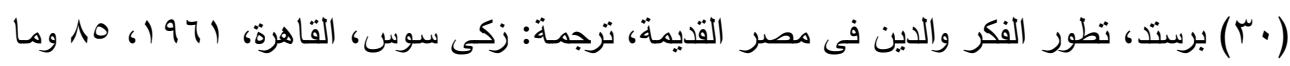

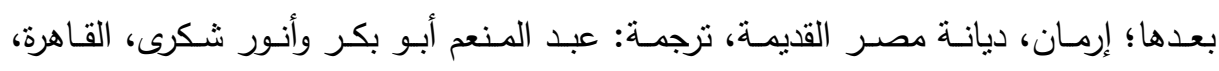
$.06199 \mathrm{~V}$ ولمزيد من التفاصيل عن الحياة بعد الموت عند قدماء المصريين: See, W. B. Kristensen, Life out of Death. Louvain, 1992.

F. Wendorf "Late Palaeolithic Sites in Egyptian Nubia" in:

F. Wendorf (ed). Prehistory of Nubia, Vol II, 1989, 954ff ؛

B. Midant-Reynes, Prēhistoire de L, ēgypte, Paris, 1992, $41 \mathrm{f}$.

J. Vandier, Manuel d'archaeoligie ēgyptienne I, Paris, 1952, 178 ؛ 
حيث حتمـت طبيعـة الأثياء قيـام هذا النظـام الذى يمثل أقدم أثـكال المجتمع الإنسـانى (') وإن ظل هذا الأمـر مجرد أطروحـة نظريـة تفتقد إلى الدليل الأثرى القاطع (؟). وربما كان وجود هذا العصر الأمومى إن إفترضنا وجوده أكثر وضوحاً فى هذه العصسور البعيدة التى كـان بـذهب فيها الرجـال لرحلات صسيد طويلـة وسبطرت الأم على حياة العائلـة(؟). حيث من المؤكد أن فكرة الأم الخصبة قد

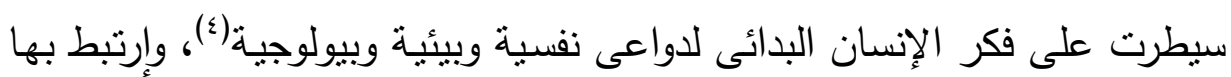
دينياً بعد أن تطورت عقائد الدين والآخرة لديه.

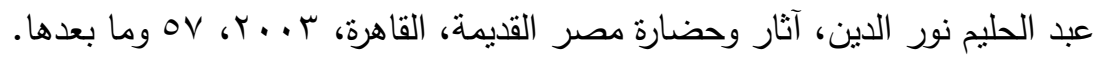

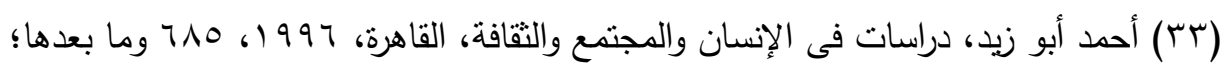

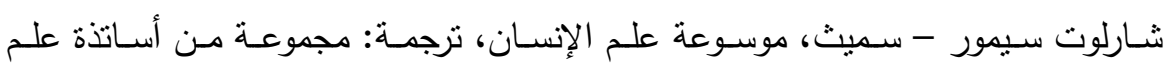

$$
\begin{aligned}
& \text { الإجتماع، القاهرة، } 991 \text { 19، • } 79 \text { وما بعدها. }
\end{aligned}
$$

( ${ }^{1}$ ) L. Woolly and J. Hawkes, op. cit., 207ff $\leqq$ H. Movies, Three Reigoins of primitive Art, New York, 1961, 39f ؛ G. Preston, "Goddess Worship" in: Encylopedia of Religion, Vol. V, 1987, 36؛ M. Eherenberg, Woman in Prehistory, London, 1989, 64.

(؟؟) عن تواتر النسب فى مصر القديمة عن الأم والاهتمام بذكرها ثم الوراثة عنها أو بوساطتها: See: Piernne, Histoire des Instittutions et du Driot Prive de Ancienne Egypte, Bruxelles, 1935, t. III, $382 \mathrm{f}$.

L. Wooly and J. Hawkes, op. cit., 207ff $\leq$ H. Movies, Three $=$ = Reigoins of Primitive Art, New York, 1961, 39f ؛ G. Preston, "Goddess Worship" in: Encylopedia of Religion, Vol. V, 1987, 36 @ M. Eherenberg, Woman in Prehistory, London, 1989, 64.

I bid., 74. ؛ E. Neumann, Op. Cit, 94. 


\section{تمثنال غير منشور من "الثرت" لإلهة الأمومة من الواحات ......أ.د. رضا محمد سيد أحمد}

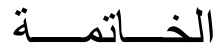

تكمن أهمية هذا التمثنال الذى عثر عليه فى مأوى صخرى بجبل الكربستال

بالصحراء البيضـاء جنوب الواحات البحرية، وبعد القرائن التى ترجح أنه من العصر الحجرى القديم الأعلى، على أن تشكيل تماثيل بدائية للإلهة الأم يضرب بجذوره فى مصر القديمـة إلى هذا العصدر ، بعد أن كان الإعتقاد السـائد لدى العلمـاء بأن أقدم نموذج معروف حتى الآن من تماثيل الإلهة الأم فى مصر يرجع إلى عصر مرمدة بنى سلامة (1)

وتكمـن أهمية هذا التمثنال أيضـاً فى تغيير مـا إعتقده العلمـاء بـأن حضـارات الثرق الأدنى القديم قد سبقت معرفتهم بتشكيل نمـاذج بدائية من تمـاثيل الإلهة الأم فى الفترة ما بين ( . . . . . . . . جق.م) للحضارة in: MDAIK 35, 1979, 53, Abb. 16 ؛ Neolithischen Siedlung Merimda - Benisalāme", 
المصرية(')، حيث أعطى هذا التمثال أفضلية السبق فى تشكيل نمـاذج بدائية من تماثيـل الإلهـة الأم للحضـارة المصـرية على حضـارات الثـرق الأدنى القـديم ولـيس العكس.

ويرجح الباحث إمكانية العثور على نماذج أخرى من نماثيل الإلهة الأم بمصر

فى الفترة الطويلة الممتدة ما بين العصر الحجرى القديم الأعلى وبين العصر الحجرى الحديث، لأننا على يقين بأن المصريين القدماء كانوا كما ذكر "هردوت" أكثر تقوى عن سـائر البشر( (r) والذين آمنـوا بالبعث والحياة الثانية منذ العصر الحجرى القديم الأعلى، وأكدوا على ذلك بالعديد من الأدوات التى وجدت مع موتاهم فى هذه العصور

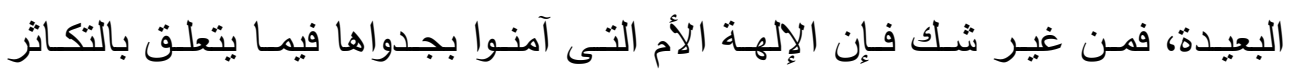

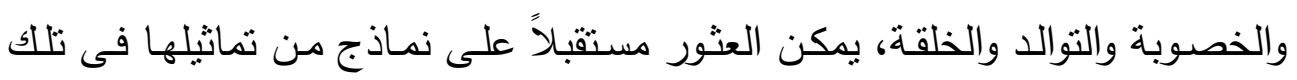
المناطق التى آوى إليها أهل هذه العصور البعيدة وبخاصـة فى الصحراء الغربية، وإن كان فرص العثور على هذه النماذج تبدو قليلة وأحياناً شبه منعدمهة، لهبوب الرياح

- M. Saleh - H. Sourouzian, The Egypt Museum Cairo, Berlin, 1988, PL., I؛ Ahmed Saied, Götterglauben und Göttheiten in der Vorgeschichte und Fruhzeit Ägypten, Cairo, 1997, 260, Taf. 183, Abb.1.

J. Mellaart, The Neolithic of the Near East, London, 1975, Table 1, z: ( $\$ ^)

$$
\text { ولمزيد من التفاصيل: انظر : أثرف زكريا المرجع السابق، بس وما بعدها. }
$$

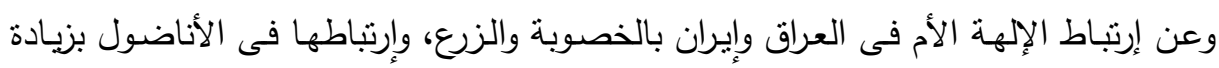

$$
\text { الإنجاب والخصوبة. }
$$

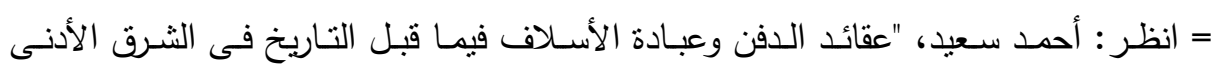
القديم"، مقال فى: دراسـات فى آثار الوطن العربى، كتاب الملتقى الثالث لجمعيـة الآثاريين

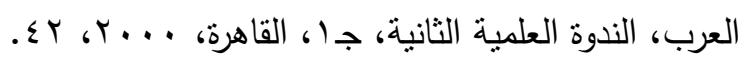

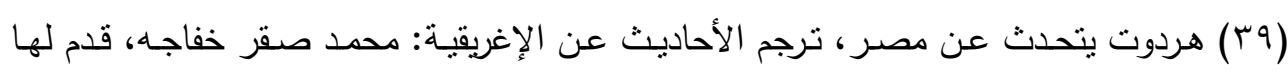

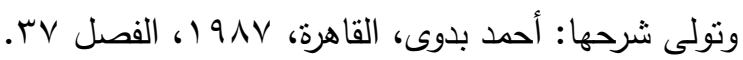


تمثال غير منشور من "الثرت" لإلهة الأمومة من الواحات .....أ.د. رضا محمد سيد أحمد

وتحرك الرمال الثديد بهذه الأماكن وأثزها السلبى على ضياع معظم مخلفات الإنسان

فى هذه العصور السحيقة.

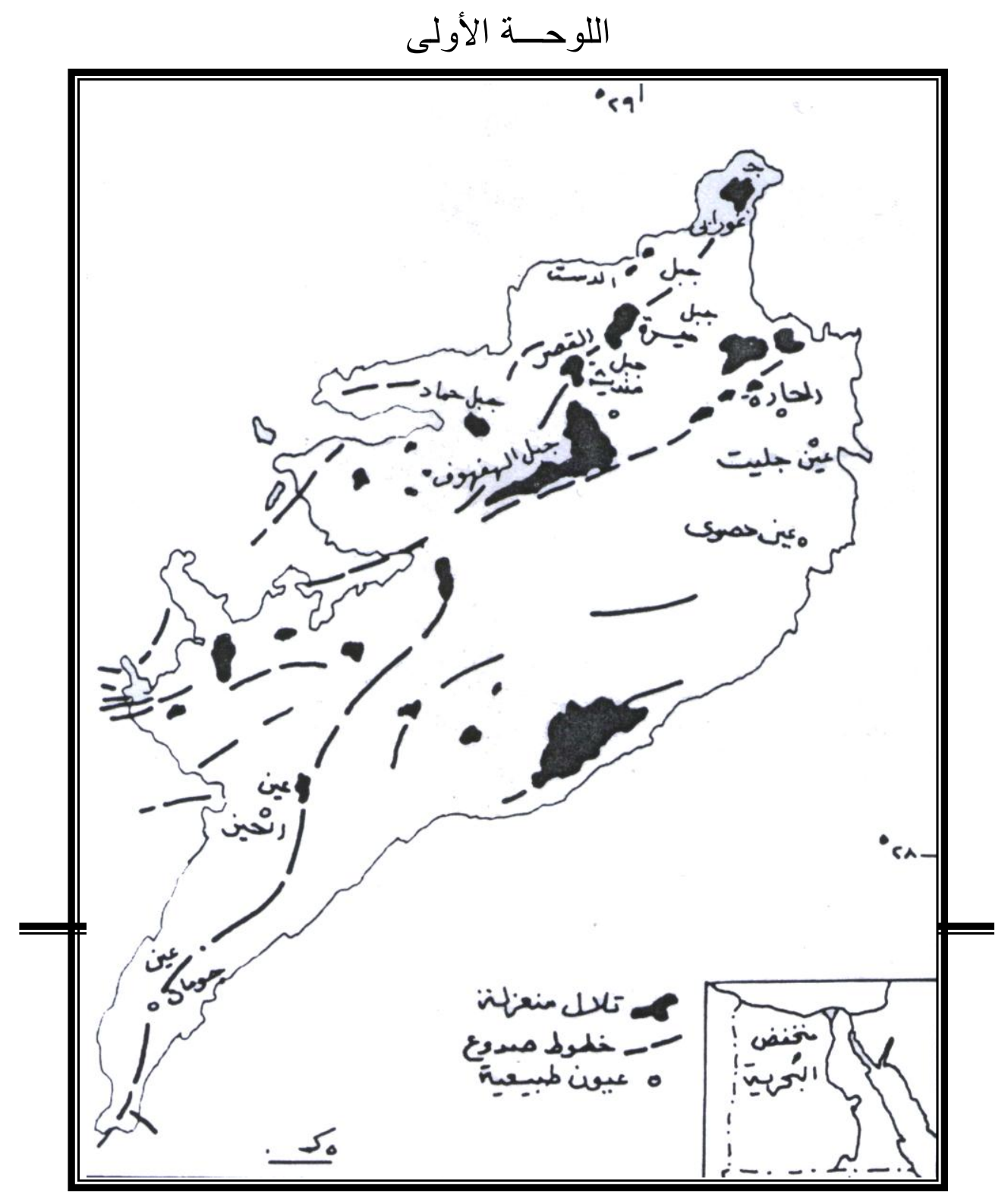




$$
\text { خريطة للواحات البحرية }
$$

عن: (محمد صبرى محسوب، جغرافية مصر الطبيعية [الجوانب الجيومورفولوجية]،

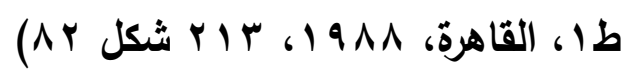

اللوحة الثانية

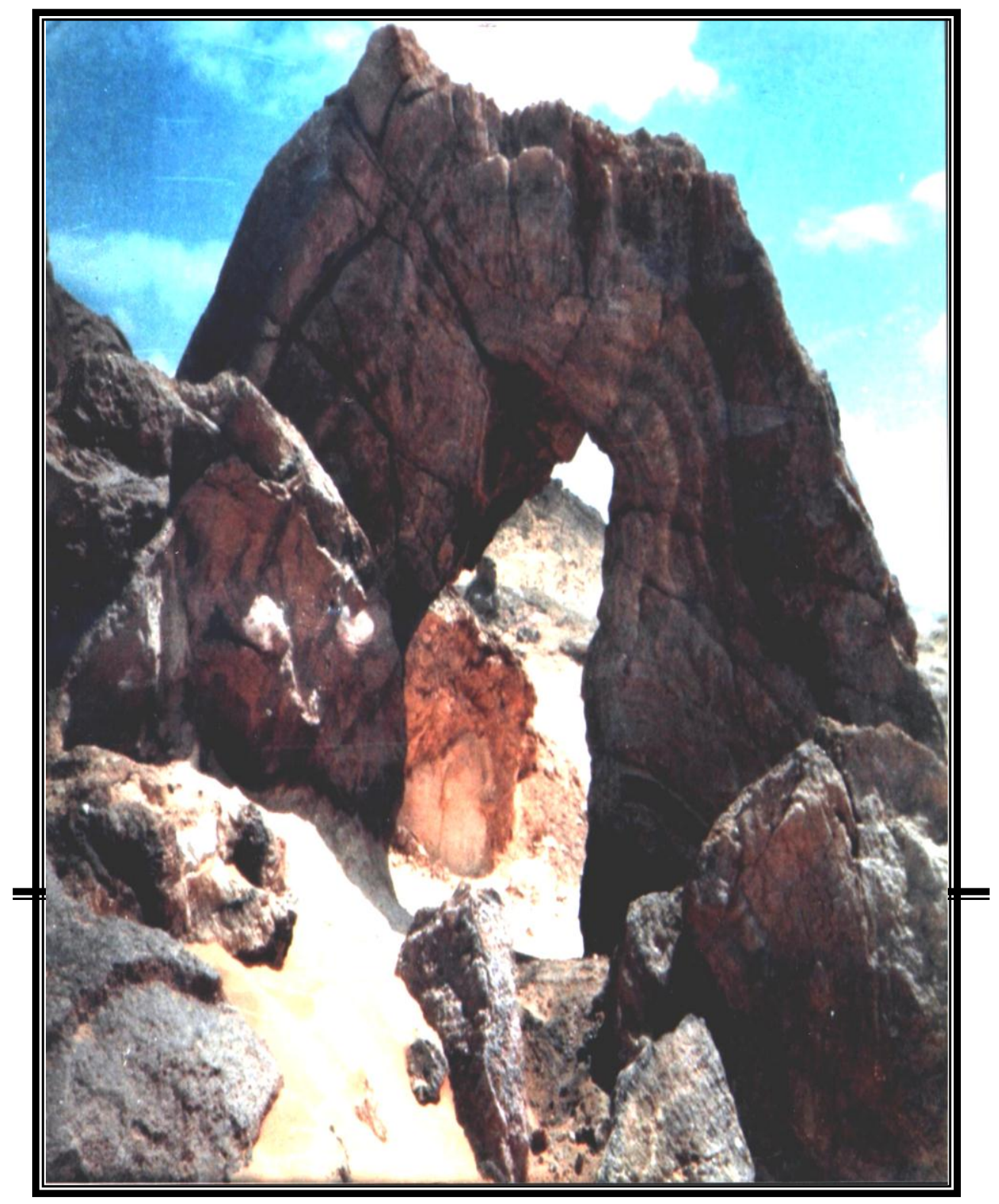


تمثال غير منشور من "الثرت" لإلهة الأمومة من الواحات .....أ.د. رضا محمد سيد أحمد

المأوى الصخرى بجبل الكريستال بالصحراء البيضاء

$$
\text { - جنوب الواحات البحرية - (لاتية }
$$

اللوحة الثالثة

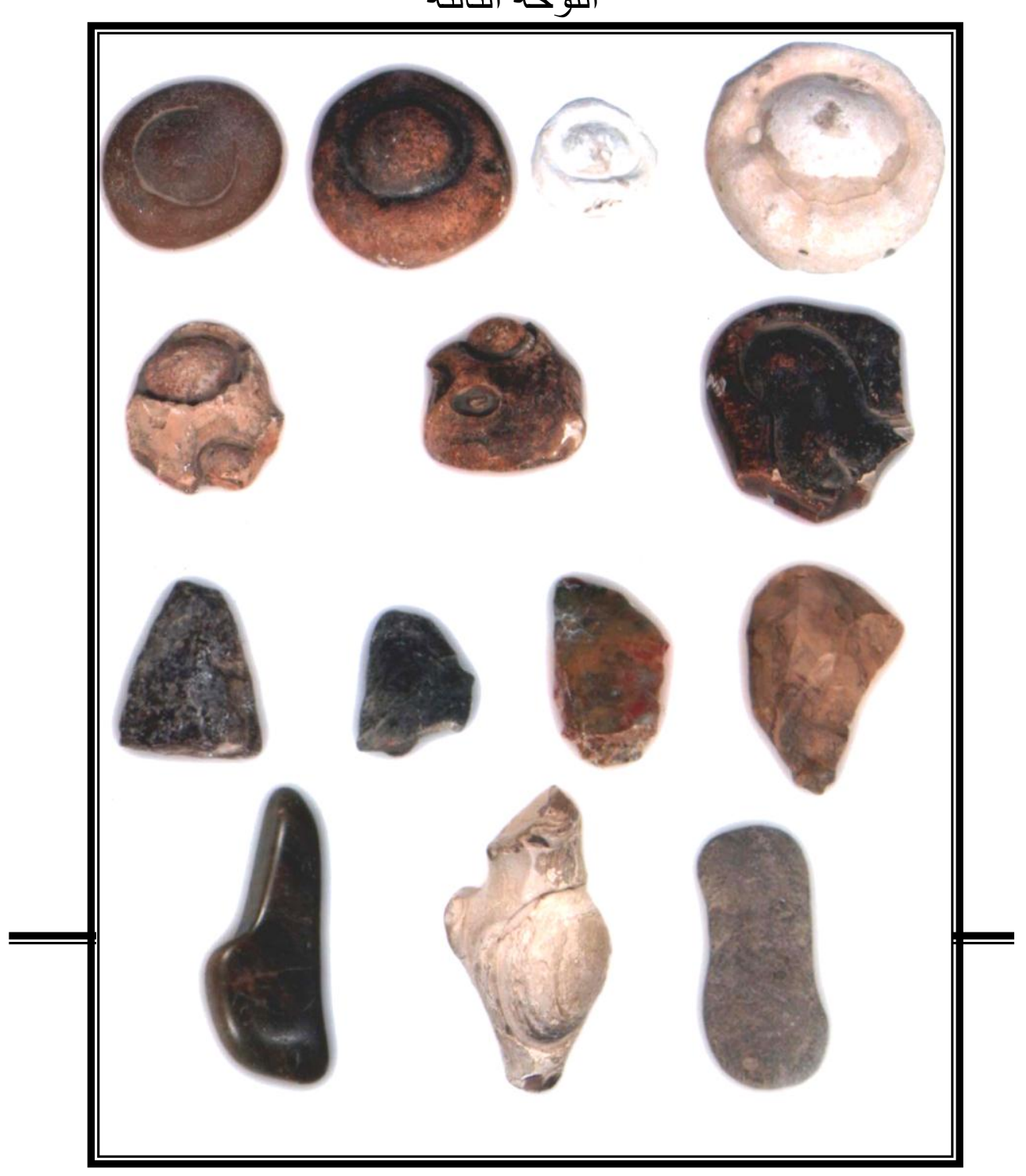


أدوات من الظران والثرت من العصر الحجرى القديم الأعلى عثر عليها بمأوى

صخرى بجبل الكريستال بالصحراء البيضاء - جنوب الواحات البحرية

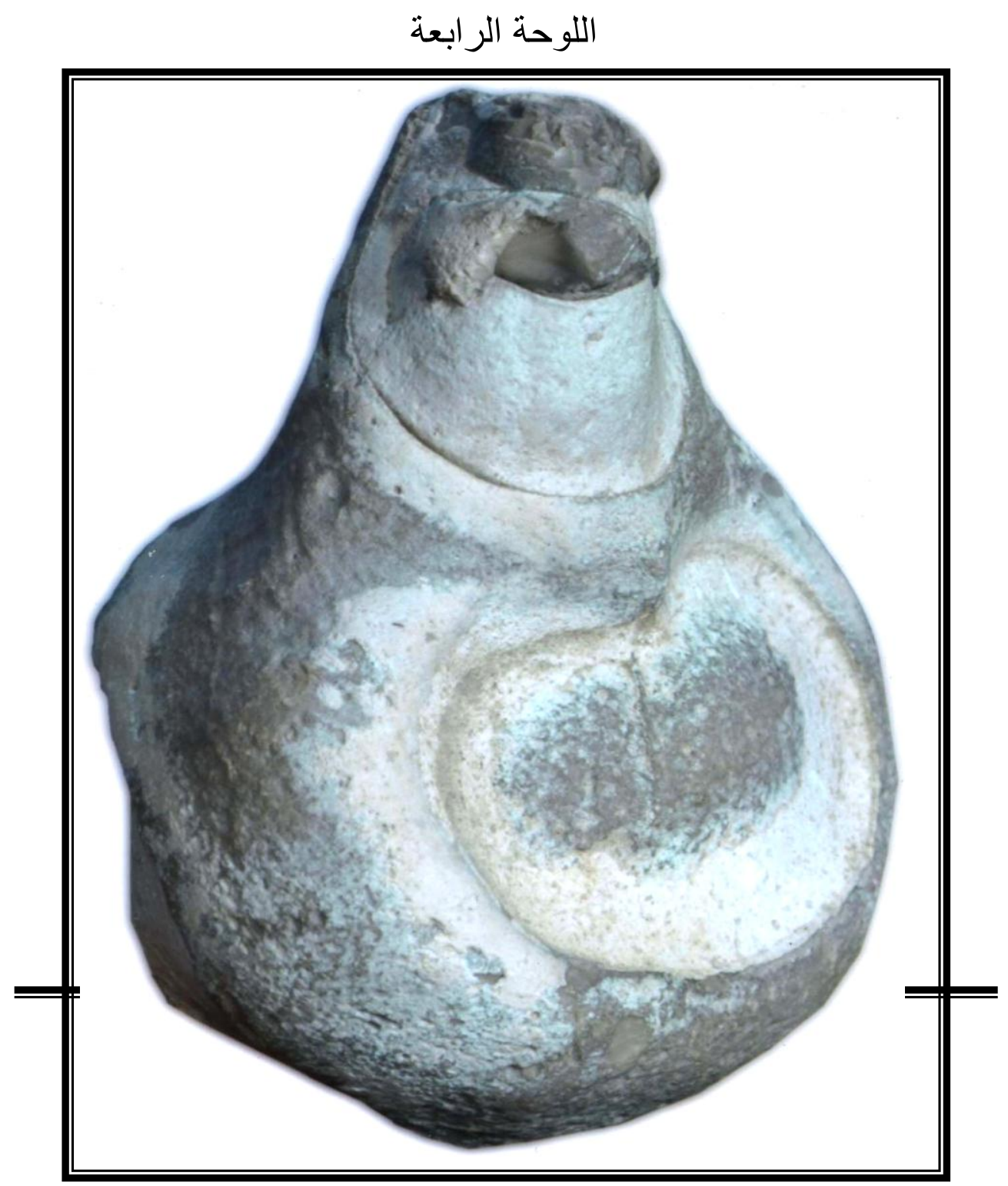




\section{تمثال غير منشور من "الثرت" لإلهة الأمومة من الواحات ..... أ.د. رضا محمد سيد أحمد}

صورة مكبرة: لتمثال إلهة الأمومة من الشرت، من مأوى صخرى

بجبل الكريستال بالصحراء البيضاء - جنوب الواحات البحرية

اللوحة الخامسة

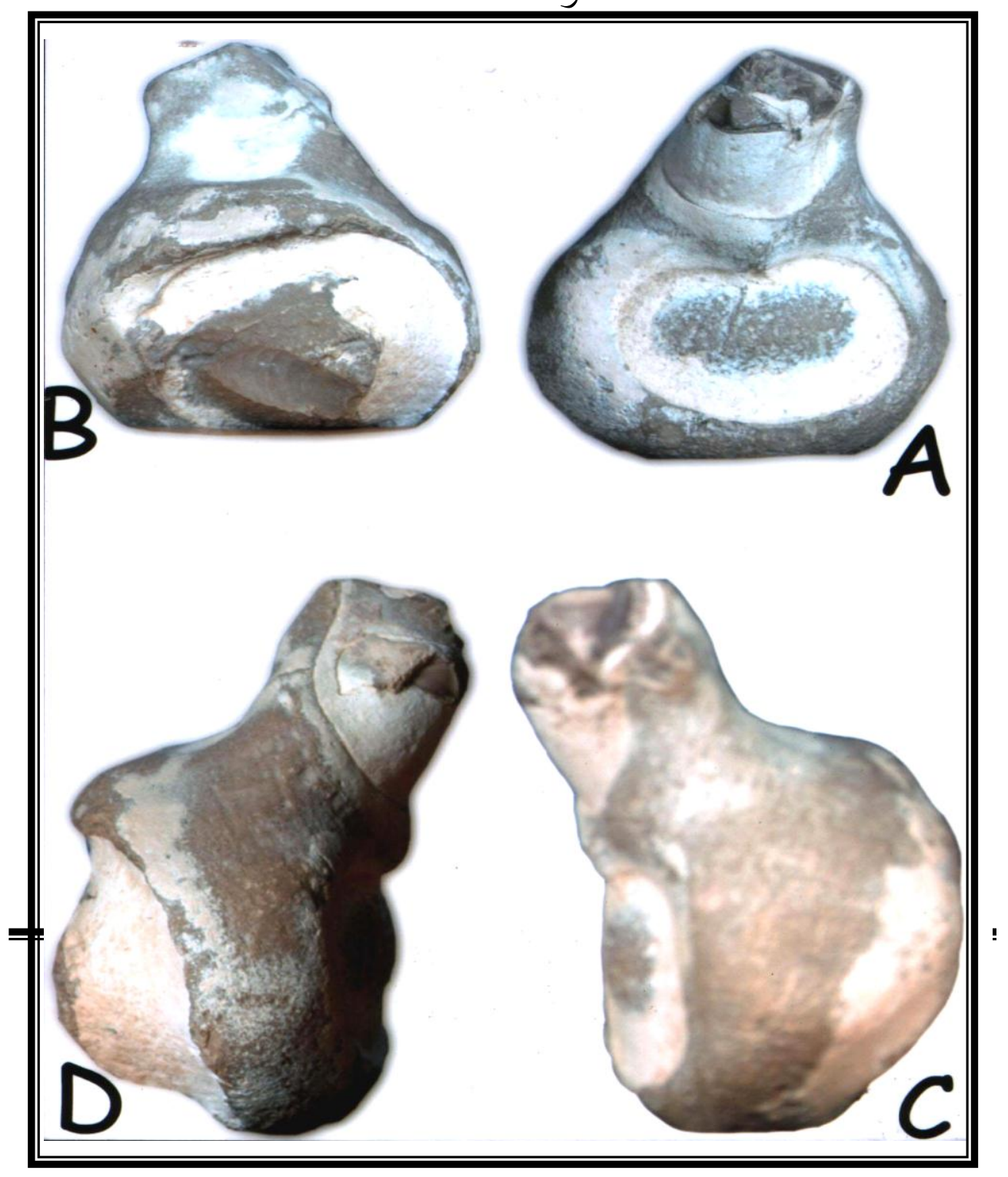




\section{التمثال من:}

B: من الخلف.

A Aن الأمام.

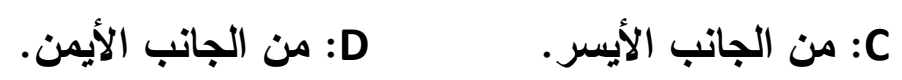

